\title{
Two Decades of (Mostly) Disappointments in Definitive Chemoradiation for Stage III Non-Small Cell Lung Cancer
}

\author{
John H Park* \\ Kansas City VA Medical Center, USA
}

Submission: March 22, 2018; Published: April 04, 2018

*Correspondence Address: John H Park, Radiation Oncologist, Clinical Assistant Professor, University of Missouri, Kansas City, 10500 Mastin St., Overland Park, KS 66212, USA, Tel: 816-922-2880; Fax: 913-227-0962; Email: john.park@va.gov

\begin{abstract}
The past two decades have little to show in the progress of definitive chemoradiation for stage III lung cancer patients. Radiation dose escalation, elective nodal irradiation, prophylactic cranial irradiation, and proton therapy have not shown to improve outcomes. The addition of surgery to the backbone of concurrent chemoradiation has also shown no benefit, except possibly in patients who can undergo a lobectomy. Consolidative chemotherapy, adjuvant gefitinib, induction chemotherapy, pemetrexed for non-squamous histologies, and the addition of cetuximab have also all failed in terms of systemic therapy. Progress has been made only recently with the addition of adjuvant durvalumab, a PD-L1 inhibitor, which significantly improved outcomes in this population and now is part of the standard of care.
\end{abstract}

Keywords: Non-small cell lung cancer; Chemoradiation; Durvalumab; Radiation therapy; Systemic therapy; Trimodality

\section{Introduction}

In the mid-1990s, several phase III trials across the world, RTOG 9410 in the United States [1], NPC 95-01 study in France [2], and the West Japanese Lung Cancer group [3], improved upon the then non-small cell lung cancer (NSCLC) treatment paradigm of sequential chemotherapy followed by radiation with the use of concurrent chemoradiation. These trials used concurrent platinum based chemotherapy with approximately $60 \mathrm{~Gy}$ of radiation. Since that time lung cancer screening has been established, stereotactic ablative radiotherapy (SABR/SBRT) has become a new paradigm for stage I NSCLC, and the driver mutation revolution is continually advancing for metastatic disease, but definitive chemoradiation (dCRT) for NSCLC has seen only one major treatment advance to standard of care after the platinum-doublet with 60 Gy of concurrent radiation in the form of adjuvant immunotherapy with the PD-L1 inhibitor durvalumab from the PACIFIC trial [4].

\section{Discussion}

The 2017 updated results of RTOG 0617, perhaps the most important dCRT NSCLC trial, is a sobering reminder of the state of dCRT in stage III NSCLC. RTOG 0617 was a 2 x 2 randomized phase III study that attempted to augment the dCRT backbone with either radiation dose escalation to $74 \mathrm{~Gy}$ or with the incorporation of cetuximab [5]. Unfortunately, the 5 year results show an overall survival (OS) and progression free survival (PFS) in favor of the $60 \mathrm{~Gy}$ arm $32.1 \%$ vs. $23 \%(p=0.004)$ and $18.3 \%$ vs. $13 \%$ ( $p=0.055)$, respectively [6]. The one improvement was that intensity modulated radiation therapy (IMRT) was found to have improved toxicity compared to 3D conformal radiation therapy (3DCRT) with less grade 3 or higher pneumonitis $7.9 \%$ v 3.5\%, respectively ( $p=.039$ ) [7]. The importance of radiation dose to the heart (V5, V35, and V40) was found to affect OS and has influenced dosimetry for current and future protocols.

Have any other radiation therapy techniques been able to improve the standard of care? A retrospective review of elective nodal irradiation (ENI) from Memorial Sloan Kettering in 2007 did not find a significant amount of failure in the unirradiated nodal volumes [8]. In the same year a randomized study from China of involved field irradiation (IFI) vs. ENI with concurrent chemotherapy (cisplatin and etoposide for 4-6 cycles) was published [9]. IFI was to a total dose of 68 vs. 74Gy and the ENI arm gave 44Gy followed by a boost of 16 - 20Gy. ENI volume included the ipsilateral hilum, mediastinum from the clavicle to $0.5-0.8 \mathrm{~cm}$ below the carina, and the supraclavicular fossa for patients with superior mediastinum metastasis. The study found an improved 5 year OS (25.1\% vs. $18.3 \%)$ in the IFI patients, thus unable to show any benefit to extended treatment volumes that could potential eradicate microscopic disease. Given the propensity for brain metastases (22-55\%) the RTOG 0214 trial looked to the addition of prophylactic cranial irradiation (PCI), 


\section{Cancer Therapy \& Oncology International Journal}

to a total dose of $30 \mathrm{~Gy}$ in 15 fractions, in trying to emulate its success in small cell lung cancer [10]. PCI improved the incidence of brain metastases at 1 year vs. observation $18.0 \%$ vs. $7.7 \%$ ( $p$ $=0.004)$, but there was no improvement in OS or disease free survival (DFS).

These studies, as well as most of radiation oncology, used photon based radiotherapy, but proton therapy has been used throughout the years with the potential for better conformality given its sharp dose distribution. A trial randomizing patients to passive scattering proton therapy vs. IMRT with the hopes to limit toxicity and improve local control found proton therapy could reduce dose to the heart, but not the mean dose to the lung or esophagus. Protons also did not improve local failure rates $10.9 \%$ vs. $10.5 \%$, IMRT vs. protons, respectively [11]. The authors do note that the proton therapy arm during the course of the trial, perhaps due to a learning curve, had a statistically significant improvement in radiation pneumonitis and that protons did reduce heart dose, perhaps eventually leading to improved OS.

Surgical intervention has also been tried to augment chemoradiation. The Intergroup (INT) 0139 investigated dCRT vs. neoadjuvant CRT to $45 \mathrm{~Gy}$ followed by surgery [12]. The MS for the dCRT was 22.2 months vs. 23.6 months in the surgical arm $(p=0.24) .5$ year OS was not statistically significant at $20 \%$ vs. $27 \%(p=0.10)$ in the dCRT vs. the surgical arm, respectively. A well known caveat to this trial is that on subset analysis, when comparing those who underwent a lobectomy only to dCRT patients, there was an improvement in survival with a MS of 33.6 months vs. 21.7 months and 5 year OS of $36 \%$ vs. $18 \%(p=0.002)$ in the lobectomy and dCRT arms, respectively. The German Lung Cancer Cooperative Group (GLCCG) trial was a convoluted trial where both arms had surgical resection [13]. Each arm had 3 cycles of induction chemotherapy followed by either twice daily concurrent chemoradiation to 45Gy (1.5 Gy BID) (intervention group) vs. surgery (control group). If resection margins were negative, the intervention group received no further therapy, but if patients had either a positive margin, received an exploratory thoracotomy, or were deemed inoperable they received single modality twice daily radiation to 24Gy (1.5 Gy BID). All the patients in the control group received single modality adjuvant radiation to either 54Gy in 1.8Gy fractions for negative margins or $68.4 \mathrm{~Gy}$ in $1.8 \mathrm{~Gy}$ fractions for positive margins. The results mimic those of the INT 0139 trial with the primary end point of PFS showing no difference between the interventional group (median PFS 9.5 months / 5 year PFS 16\%) vs. control group (median PFS 10.0 months / 5 year PFS 14\%) ( $p=0.87$ ) and a caution against pneumonectomies after induction CRT. The recently published ESPATUE study randomized patients after 3 cycles of induction cisplatin $50 \mathrm{mg} / \mathrm{m}^{2}$ and paclitaxel $175 \mathrm{mg} /$ $\mathrm{m}^{2}$ (days 1 and 8 every 21 days) and concurrent chemoradiation with a cisplatin $50 \mathrm{mg} / \mathrm{m}^{2}$ and vinorelbine $20 \mathrm{mg} / \mathrm{m}^{2}$ (day 2 and 9) to 45 Gy in $1.5 \mathrm{~Gy}$ fractions BID to definitive radiation boost dose of 20 - 26Gy in 2Gy fractions or surgical resection [14]. There was no difference in 5 year OS $40 \%$ vs. $44 \%$ ( $p=0.34$ ) or PFS $35 \%$ or $32 \%(p=0.75)$ between the dCRT and surgical arms, respectively.

The story of systemic therapy has also been disappointing with the exception of the previously mentioned PACIFIC trial. The Hoosier Oncology Group, in a phase II study, randomized dCRT patients to consolidative docetaxel $75 \mathrm{mg} / \mathrm{m}^{2}$ IV every 21 days [15]. The median survival was 23.2 months in the observation arm vs. 21.2 months for the consolidative docetaxel ( $p=0.883$ ). The SWOG S9504 was a single arm study that also explored 3 cycles of the same dose of docetaxel that showed a promising 5 year OS of $29 \%$ [16]. The follow up trial SWOG S0023 added gefitinib $500 \mathrm{mg}$ (later $250 \mathrm{mg}$ ) or placebo orally daily for five years or until progression or patient intolerance [17]. Unfortunately, gefitinib was shown to have a detriment to survival with a MS of 23 months vs. 35 months in the placebo arm ( $p=0.013$ ). More recently the KCSG-LU05-04 also attempted to add adjuvant docetaxel and cisplatin doublet $\left(35 \mathrm{mg} / \mathrm{m}^{2}\right.$ each on days 1 and 8, every 3 weeks) to dCRT [18]. The primary endpoint of the trial was PFS. The median PFS of the adjuvant docetaxel and cisplatin arm was 9.1 vs. 8.1 months in the observation arm $(p=0.36)$. The median OS was 21.8 in the treatment arm and 20.6 in the observation arm $(p=0.44)$.

The Cancer and Leukemia Group B (CALGB) 39801 evaluated neoadjuvant therapy with two cycles of carboplatin AUC 6 and paclitaxel $200 \mathrm{mg} / \mathrm{m}^{2}$ every 21 days prior to dCRT [19]. There was no difference in either MS 12 vs. 14 months or 2 year OS $29 \%$ vs. $31 \%$, in the dCRT only vs. consolidative arms, respectively ( $p=0.3$ ). The PROCLAIM trial attempted to improve outcomes by selectively treating non-squamous cell NSCLC with pemetrexed. Pemetrexed $500 \mathrm{mg} / \mathrm{m}^{2}$ with cisplatin $75 \mathrm{mg} / \mathrm{m}^{2}$ was given IV every 3 weeks concurrently followed by four cycles of consolidation pemetrexed $500 \mathrm{mg} / \mathrm{m}^{2}$ IV every 3 weeks [20]. This was compared to dCRT with cisplatin \& etoposide followed by two cycles of standard platinum based doublets (cisplatin/ etoposide, cisplatin/vinorelbine, or carboplatin/paclitaxel). 3 year OS was $40 \%$ vs. $37 \%$ with MS of 26.8 vs. 25.0 months $(\mathrm{p}=0.831)$ showing no difference between the pemetrexed vs. standard arm, respectively. The previously mentioned RTOG 0617 trial added cetuximab, a chimerized IgG1 subclass monoclonal antibody to epidermal growth factor receptor (EGFR, HER1, c-ErbB-1), to dCRT [5]. Just as dose escalation in this trial was ineffective, the MS of those receiving cetuximab was 25.0 months vs. 24.0 months in the no cetuximab arm ( $p=$ $0.29)$.

Amongst all these negative trials, the addition of adjuvant durvalumab is one of the only improvements that have been incorporated into the NCCN guidelines as a standard for dCRT patients [21]. The PACIFIC trial randomized patients to durvalumab $10 \mathrm{mg}$ per kilogram vs. placebo as consolidation after 


\section{Cancer Therapy \& Oncology International Journal}

the completion of dCRT every two weeks for up to 12 months [4]. The median PFS was 16.8 months in the immunotherapy arm vs. 5.6 months in the placebo arm and the 18 month PFS was $44.2 \%$ vs. $27.0 \%$ in the durvalumab and placebo arms respectively ( $p<$ $0.001)$. The trial has not matured enough for OS data, but median time to death or distant metastasis was greater with durvalumab at 23.2 months than 14.6 months seen with placebo $(p<0.001)$. These results were applicable irrespective of baseline PD-L1 expression.

\section{Conclusion}

In conclusion, the standard of care for stage III patients undergoing definitive chemoradiation is dCRT to 60 Gy via IMRT using conscientious heart dose constraints with a platinum doublet followed by durvalumab. Future studies are looking at the addition of SABR [22], hypofractionated concurrent chemoradiation (NCT02619448), PET adaptive radiotherapy (RTOG 1106), individualized treatment based on driver mutation analysis (RTOG 1306), adjuvant nivolumab (RTOG 3505), metformin with dCRT (NRG-LU001), or improved proton techniques using Intensity-Modulated Scanning Beam Proton Therapy (IMPT) With Simultaneous Integrated Boost (SIB) (NCT01629498). Hopefully, the next two decades will bring much needed improvements for our patients.

\section{References}

1. Curran W, Paulus R, Langer CJ, Komaki R, Lee JS, et al. (2011) Sequential vs. concurrent chemoradiation for stage III non-small cell lung cancer: randomized phase III trial RTOG 9410. J Natl Cancer Inst 103(19): $1452-1460$

2. Fournel P, Robinet G, Thomas P, Souquet PJ, Léna H, et al. (2005) Randomized phase III trial of sequential chemoradiotherapy compared with concurrent chemoradiotherapy in locally advanced non-smallcell lung cancer: Groupe Lyon-Saint-Etienne d'Oncologie ThoraciqueGroupe Français de Pneumo-Cancérologie NPC 95-01 Study. J Clin Oncol 23(25): 5910-5917.

3. Furuse K, Fukuoka M, Kawahara M, Nishikawa H, Takada Y, et al. (1999) Phase III study of concurrent versus sequential thoracic radiotherapy in combination with mitomycin, vindesine, and cisplatin in unresectable stage III non-small-cell lung cancer. J Clin Oncol 17(9): 2692-2699.

4. Antonia SJ, Villegas A, Daniel D, Vicente D, Murakami S, et al. (2017) Durvalumab after Chemoradiotherapy in Stage III Non-Small-Cell Lung Cancer. N Engl J Med 377(20): 1919-1929.

5. Bradley JD, Paulus R, Komaki R, Masters G, Blumenschein G, et al. (2015) Standard-dose versus high-dose conformal radiotherapy with concurrent and consolidation carboplatin plus paclitaxel with or without cetuximab for patients with stage IIIA or IIIB non-small-cell lung cancer (RTOG 0617): a randomised, two-by-two factorial phase 3 study. Lancet Oncol 16(2): 187-199.

6. Bradley JD, Hu C, Komaki R, Masters G, Blumenschein G, et al. (2017) Long-Term Results of RTOG 0617: A Randomized Phase 3 Comparison of Standard Dose versus High Dose Conformal Chemoradiation Therapy + /- Cetuximab for Stage III NSCLC. Int J Radiat Oncol Biol Phys 99(2): S105.

7. Chun SG, Hu C, Choy H, Komaki RU, Timmerman RD, et al. (2017) Impact of Intensity-Modulated Radiation Therapy Technique for Locally Advanced Non-Small-Cell Lung Cancer: A Secondary Analysis of the NRG Oncology RTOG 0617 Randomized Clinical Trial. J Clin
Oncol 35(1): 56-62.

8. Rosenzweig KE, Sura S, Jackson A, Yorke E (2017) Involved-field radiation therapy for inoperable non small-cell lung cancer. J Clin Oncol 25(35): 5557-5561.

9. Yuan S, Sun X, Li M, Yu J, Ren R, et al. (2007) A randomized study of involved-field irradiation versus elective nodal irradiation in combination with concurrent chemotherapy for inoperable stage III nonsmall cell lung cancer. Am J Clin Oncol 30(3): 239-244.

10. Gore EM, Bae K, Wong SJ, Sun A, Bonner JA, et al. (2011) Phase III comparison of prophylactic cranial irradiation versus observation in patients with locally advanced non-small-cell lung cancer: primary analysis of radiation therapy oncology group study RTOG 0214. J Clin Oncol 29(3): 272-278.

11. Liao Z, Lee JJ, Komaki R, Gomez DR, O’Reilly MS (2018) Bayesian Adaptive Randomization Trial of Passive Scattering Proton Therapy and Intensity-Modulated Photon Radiotherapy for Locally Advanced Non-Small-Cell Lung Cancer. J Clin Oncol 2: JCO2017740720.

12. Albain KS, Swann RS, Rusch VW, Turrisi AT, Shepherd FA, et al. (2009) Radiotherapy plus chemotherapy with or without surgical resection for stage III non-small-cell lung cancer: a phase III randomised controlled trial. Lancet 374(9687): 379-386.

13. Thomas M, Rübe C, Hoffknecht P, Macha HN, Freitag L, et al. (2008) Effect of preoperative chemoradiation in addition to preoperative chemotherapy: a randomised trial in stage III non-small-cell lung cancer. Lancet Oncol 9(7): 636-648.

14. Eberhardt WE, Pöttgen C, Gauler TC, Friedel G, Veit S (2015) Phase III Study of Surgery Versus Definitive Concurrent Chemoradiotherapy Boost in Patients With Resectable Stage IIIA(N2) and Selected IIIB NonSmall-Cell Lung Cancer After Induction Chemotherapy and Concurrent Chemoradiotherapy (ESPATUE). J Clin Oncol 33(35): 4194-4201.

15. Hanna N, Neubauer M, Yiannoutsos C, McGarry R, Arseneau J, et al (2008) Phase III study of cisplatin, etoposide, and concurrent chest radiation with or without consolidation docetaxel in patients with inoperable stage III non-small-cell lung cancer: the Hoosier Oncology Group and U.S. Oncology. J Clin Oncol 26(35): 5755-5760.

16. Gandara DR, Chansky K, Albain KS, Gaspar LE, Lara PN, et al. (2006) Long-term survival with concurrent chemoradiation therapy followed by consolidation docetaxel in stage IIIB non-small-cell lung cancer: a phase II Southwest Oncology Group Study (S9504). Clin Lung Cancer 8(2): 116-121.

17. Kelly K, Chansky K, Gaspar LE, Albain KS, Jett J, et al. (2008) Phase III trial of maintenance gefitinib or placebo after concurrent chemoradiotherapy and docetaxel consolidation in inoperable stage III non-small-cell lung cancer: SWOG S0023. J Clin Oncol 26(15): 24502456.

18. Ahn JS, Ahn YC, Kim JH, Lee CG, Cho EK, et al. (2015) Multinational Randomized Phase III Trial With or Without Consolidation Chemotherapy Using Docetaxel and Cisplatin After Concurrent Chemoradiation in Inoperable Stage III Non-Small-Cell Lung Cancer: KCSG-LU05-04. J Clin Oncol 33(24): 2660-2666.

19. Vokes EE, Herndon JE, Kelley MJ, Cicchetti MG, Ramnath N, et al. (2007) Induction chemotherapy followed by chemoradiotherapy compared with chemoradiotherapy alone for regionally advanced unresectable stage III Non-small-cell lung cancer: Cancer and Leukemia Group B. J Clin Oncol 25(13): 1698-1704.

20. Senan S, Brade A, Wang LH, Vansteenkiste J, Dakhil S, et al. (2016) PROCLAIM: Randomized Phase III Trial of Pemetrexed-Cisplatin or Etoposide-Cisplatin Plus Thoracic Radiation Therapy Followed by Consolidation Chemotherapy in Locally Advanced Nonsquamous NonSmall-Cell Lung Cancer. J Clin Oncol 34(9): 953-962. 


\section{Cancer Therapy \& Oncology International Journal}

21. National Comprehensive Cancer Network (2018) Non-Small Cell Lung Cancer.

22. Feddock J, Arnold SM, Shelton BJ, Sinha P, Conrad G, et al. (2013) Stereotactic body radiation therapy can be used safely to boost residual

This work is licensed under Creative Commons Attribution 4.0 License

DOI: 10.19080/CTOIJ.2018.10.555780 disease in locally advanced non-small cell lung cancer: a prospective study. Int J Radiat Oncol Biol Phys 85(5): 1325-1331.

Your next submission with Juniper Publishers will reach you the below assets

- Quality Editorial service

- Swift Peer Review

- Reprints availability

- E-prints Service

- Manuscript Podcast for convenient understanding

- Global attainment for your research

- Manuscript accessibility in different formats (Pdf, E-pub, Full Text, Audio)

- Unceasing customer service

Track the below URL for one-step submission https://juniperpublishers.com/online-submission.php 